\title{
Produção e purificação parcial de PPD-maleína para diagnóstico do mormo em equídeos ${ }^{1}$
}

\author{
Karla P.C. da Silva ${ }^{2 *}$, Galba M.C. Takaki ${ }^{3}$, José A.A. Teles ${ }^{4}$, Antônio F.M. Dantas ${ }^{5}$, \\ Mateus M. Costa ${ }^{6}$, Wagnner P. Felix ${ }^{6}$ e Rinaldo A. Mota ${ }^{7}$
}

\begin{abstract}
Silva K.P.C., Takaki G.M.C., Teles J.A.A., Dantas A.F.M., Costa M.M., Felix W.P. \& Mota R.A. 2014. [Partially purified malleo-proteins production for glanders diagnosis in Equidae.] Produção e purificação parcial de PPD-maleína para diagnóstico do mormo em equídeos. Pesquisa Veterinária Brasileira 34(1):57-61. Laboratório de Doenças Infecciosas dos Animais, Faculdade de Veterinária, Unidade Educacional Viçosa, Campus Arapiraca, Universidade Federal de Alagoas, Fazenda São Luiz s/n, Zona Rural de Viçosa, Viçosa, AL 57700-000, Brazil. E-mail: karla.ufal@gmail.com

The objective of this study was to produce and partially purify Malleo-protein from Burkholderia mallei samples isolates from Equidae in Brazil with potential for use in the diagnosis of glanders. The strain B. mallei phenotypically characterized and proven virulent was inoculated into broth Dorset-Henley to grow and metabolize. The proteins were separated by trichloroacetic acid precipitation and amonium sulfate precipitation. The PPD mallein was concentrated $1.0 \mathrm{mg} / \mathrm{mL}$ and biologically tested in guinea pigs. It was effective in the development of delayed-type hypersensitivity and consequently to identify true-positive animals and to exclude of true negatives. There is the possibility for potential use in the glanders diagnosis in Equidae.
\end{abstract}

INDEX TERMS: Mallein test, glanders, Burkholderia mallei, diagnosis, PPD-mallein.

RESUMO.- Objetivou-se com este estudo produzir e purificar parcialmente a PPD-maleína a partir de amostras de Burkholderia mallei isoladas de equídeos no Brasil com potencial para uso no diagnóstico do mormo. As linhagens de B. mallei fenotipicamente caracterizadas e de virulência comprovada foram inoculadas em caldo Dorset-Henley para crescer e me-

\footnotetext{
${ }^{1}$ Recebido em 4 de outubro de 2013.

Aceito para publicação em 11 de dezembro de 2013.

${ }^{2}$ Departamento de Medicina Veterinária, Universidade Federal de Alagoas (UFAL), Fazenda São Luiz s/n, Zona Rural de Viçosa, Viçosa, AL 57700-000, Brasil.*Autor para correspondência: karla.ufal@gmail.com

${ }^{3}$ Núcleo de Pesquisas em Ciências Ambientais, Universidade Católica de Pernambuco (Unicap), Rua do Príncipe 526, Boa Vista, Recife, PE 50050900, Brasil.

${ }^{4}$ Medicina Veterinária, Fundação Educacional Jayme de Altavila, Rodovia Divaldo Suruagy s/n, Marechal Deodoro, AL 57160-000, Brasil.

${ }^{5}$ Medicina Veterinária, Universidade Federal de Campina Grande (UFCG), Campus de Patos, Cx. Postal 64, Patos, PB 58700-970, Brasil.

${ }^{6}$ Colegiado Medicina Veterinária, Universidade Federal do Vale do São Francisco (Univasf), Rodov. BR-407 Km 12, Lote 543, Projeto de Irrigação Senador Nilo Coelho s/n, C1, Petrolina, PE 56300-990, Brasil.

${ }^{7}$ Laboratório de Bacteriologia Veterinária, Departamento de Medicina Veterinária, Universidade Federal Rural de Pernambuco (UFPE), Rua Dom Manuel de Medeiros s/n, Dois Irmãos, Recife, PE 52171-900, Brasil. E-mail: rinaldo.mota@gmail.com
}

tabolizar. Em seguida, as proteínas foram separadas por precipitação com ácido tricloroacético e precipitadas com sulfato de amônia. As PPDs-maleínas foram concentradas em 1,0mg/ $\mathrm{mL}$ e na avaliação realizada em cobaios foi eficaz no desenvolvimento da hipersensibilidade do tipo tardia e consequentemente na identificação de animais verdadeiro positivos e exclusão dos verdadeiro negativos, sendo uma possibilidade em potencial para utilização no diagnóstico do mormo.

TERMOS DE INDEXAÇÃO: Maleinização, mormo, Burkholderia mallei, diagnóstico, PPD-maleina.

\section{INTRODUÇÃO}

O mormo é considerado a principal doença bacteriana dos equídeos, sendo transmissível ao homem e a outras espécies animais. Registrada sua reemergência no Brasil (Mota et al. 2000), atualmente a doença constitui um sério problema sanitário para os equídeos das regiões Norte e Nordeste do País (Mota et al. 2005, Brasil 2008).

O Ministério da Agricultura Pecuária e Abastecimento do Brasil (MAPA) indica o diagnóstico oficial da doença em equídeos, a técnica de Fixação do Complemento (FC) como teste de triagem e a maleinização para confirmar os casos positivos ou inconclusivos na FC (OIE 2008). 
A FC possui o entrave da padronização insuficiente do antígeno que pode comprometer a qualidade do teste (Verma et al. 1990, Naureen et al. 2007), conduzindo a limitações quanto à especificidade e sensibilidade da técnica e alguns autores questionam sua eficácia e aplicabilidade (Neubauer et al. 2005, Naureen et al. 2007). Outra limitação está relacionada aos soros de muares, asininos e éguas prenhes que devem ser inativados para evitar atividade anticomplementar. Esses fatores são limitantes à exequibilidade do teste uma vez que inviabiliza a amostra e requer uma nova coleta de soro (Brasil 2004).

A maleinização utiliza como reagente um derivado protéico purificado (PPD-maleína) maleína que se encontra disponível comercialmente. Consiste em uma solução de frações protéicas de $B$. malei solúveis ativamente produzidas durante o crescimento bacteriano em meio líquido e tratadas pelo calor. 0 ensaio se baseia na detecção da reação de hipersensibilidade do tipo IV ou Tardia (HTT) nos equídeos infectados (OIE 2008).

De acordo com Verma et al. (1994) e Neubauer et al. (2005), a maleinização utilizando a PPD-maleína é a técnica de maior especificidade quando comparado a outras técnicas de diagnóstico do mormo. Entretanto o maior entrave para a utilização da maleinização em alta escala é a dificuldade na aquisição e o valor do imunógeno importado, limitando o seu uso na elucidação dos casos suspeitos e positivos.

Objetivou-se com esse estudo produzir, purificar e avaliar a PPD-maleína a partir de amostras bacterianas isoladas no território nacional com potencial para uso no diagnóstico do mormo.

\section{MATERIAL E MÉTODOS}

As amostras de Burkholderia mallei foram obtidas a partir do conteúdo purulento de nódulos cutâneos de equídeos com diagnóstico clínico e sorológico positivo para o mormo nos estados de Pernambuco e Alagoas, Brasil. Para o isolamento bacteriano, as amostras clínicas foram semeadas em placas de Petri contendo ágar base enriquecido com sangue de ovino. Em seguida as placas foram incubadas em estufa bacteriológica a $37^{\circ} \mathrm{C}$ por 48 horas (OIE 2008). As colônias bacterianas com características morfológicas semelhantes a B. mallei foram confirmadas por caracterização fenotípica e molecular (Burtnick et al. 2002, Mota et al. 2005).

Foram produzidas, a partir das amostras de B. mallei identificadas, duas PPDs-maleínas, sendo a primeira a partir da estirpe de B. mallei isolada no estado Pernambuco e a segunda a partir da amostra proveniente do estado de Alagoas. Para a produção da PPD-maleína, as amostras foram ressuspendidas em solução salina $(0,85 \%)$ e inoculadas em meio Dorset modificado. Posteriormente, o meio foi incubado a $37^{\circ} \mathrm{C}$ sob agitação durante oito semanas. Após o período incubação, realizou-se a esterilização em banho-maria a $100^{\circ} \mathrm{C}$ por três horas e em seguida filtrado em membrana $(0,2 \mu \mathrm{m})$ para remover as células bacterianas e substâncias grosseiras. Obteve-se a maleína por meio da precipitação e purificação ácida, utilizando-se ácido tricloroacético e sulfato de amônia

A maleína concentrada foi centrifugada e o sobrenadante diluído em igual quantidade de solução tampão de glicose. A PPD-maleína de concentração conhecida foi então colocada em ampolas esterilizadas e resfriadas (Verma et al. 1994, OIE 2008).

Foram utilizados três momentos para monitorar a concentração de proteínas no processo de produção da maleína. 0 momento um ocorreu após a esterilização e filtração do líquido metabólico; as amostras para compor o momento dois foram obtidas após a precipitação e lavagem das proteínas e o momento três foi realizado depois de concluída a purificação parcial da PPD-maleína.

Para dosagem das proteínas utilizou-se o Kit de análise de proteínas totais (Proteínas Totais - Bioquímica Clínica Doles) e a leitura foi realizada em espectofotômetro (Biochrom - libra S32). A concentração do produto final da maleína foi ajustada de acordo com o preconizado pela OIE (2008) para utilização no teste de diagnóstico.

Realizou-se eletroforese em SDS-PAGE do extrato protéico de B. mallei utilizando-se gel de poliacrilamida para eletroforese sob condições desnaturantes, conforme descrição de Laemmli (1970). Para tal foi utilizado sistema de eletroforese miniVE (Amershan Biosciences). As condições para corrida foram $80 \mathrm{~V}$ sob amperagem constante por aproximadamente $1 \mathrm{~h}$. Após a corrida eletroforética o gel foi corado com Coomassie blue para a visualização das bandas protéicas.

Para controle do produto cada lote de maleína foi testado quanto à segurança, esterilidade e potência. As preparações contendo o fenol como conservante foram padronizadas na concentração de $0,5 \%$.

Avaliou-se a potência das PPDs-maleínas em 20 cobaios ( $C a-$ via porcellus) sensibilizados (G1) por via sub-cutânea com $0,1 \mathrm{ml}$ do antígeno inativado de B. mallei (concentração de $5 \mathrm{mg} / \mathrm{ml}$ ). Os animais foram mantidos durante 30 dias sob idênticas condições de ambiente e nutrição para posterior avaliação da PPD-maleína.

Colheu-se o sangue dos cobaios antes da maleinização para confirmar o desenvolvimento da resposta imune adquirida frente à bactéria inativada, através da prova sorológica de fixação do complemento.

Os animais foram tricotomizados na região intercostal direita e esquerda onde foram inoculadas a PPD-maleína 1 (flanco esquerdo) e PPD-maleína 2 (flanco direito). Inoculou-se $0,1 \mathrm{ml}$ da maleína teste por via intradérmica e a comprovação da inoculação foi feita por meio da observação da formação de pápula intradérmica.

A segurança da PPD-maleína foi avaliada em outro grupo de 20 cobaios (G2) não sensibilizados com a bactéria. Esses animais também foram inoculados com $0,1 \mathrm{ml}$ de cada PPD-maleína por via intradérmica, utilizando-se o mesmo procedimento empregado no G1. Os animais foram identificados pela sigla "C" (cobaio) seguida pelo número do animal e o lado da inoculação "E ou D" (esquerdo e direito), para posterior avaliação da reação alérgico-cutânea (Verma et al., 1994). Todos os procedimentos de avaliação da PPD-maleína quanto à esterilidade, segurança, potência, concentração do conservante seguiram as recomendações da OIE (2008).

As áreas de aplicação foram avaliadas às 24, 48 e 72 horas após a inoculação, medindo-se o diâmetro transverso da área inflamatória palpável. O local de aplicação das maleínas foi avaliado quanto à consistência, presença e dimensão do edema, sensibilidade à palpação e aumento da temperatura local. Observou-se também o estado geral do animal, anotando-se os achados clínicos.

Foram colhidos fragmentos de pele dos cobaios do G1 e G2 que foram fixados em solução de formol tamponado a 10\%. Esse material foi clivado, processado rotineiramente e incluídos em parafina. Em seguida foram realizados cortes histopatológicos de aproximadamente $5 \mu \mathrm{m}$ de espessura e as lâminas confeccionadas e coradas pela hematoxilina e eosina para posterior análise histológica.

\section{RESULTADOS E DISCUSSÃO}

As bactérias identificadas apresentaram perfil fenotípico e genotípico que permitiu classificá-las como Burkholderia 
mallei, com características idênticas às observadas anteriormente por Yabuuchi et al. (1992), Mota et al. (2005), Silva et al. $(2008,2009)$.

Quanto à dosagem das proteínas observou-se que durante o processamento das amostras, a concentração protéica aumentou gradativamente nas duas PPD-maleínas. De acordo com Amemiya et al. (2007), Al-Ani \& Roberson (2007), a PPD-maleína deve ter concentração de proteínas ajustadas para uso na maleinização não inferior a $0,95 \mathrm{mg} /$ $\mathrm{ml}$ e não mais que $1,05 \mathrm{mg} / \mathrm{ml}$. Após a produção das PPDs-maleína estas foram ajustadas para $1,0 \mathrm{mg} / \mathrm{ml}$, de acordo com recomendação da OIE (2008).

A precipitação e separação das proteínas com ácido tricloroacético associado ao sulfato de amônia proporcionaram a obtenção de um produto final de alto valor maleinogênico. De acordo com Verma et al. (1994) e Naureen et al. (2007) o processo de precipitação e separação induz a produção e isolamento de proteínas ativas de alto peso molecular que são responsáveis pela potência da reação de maleinização sem efeitos colaterais e inespecíficos, ao mesmo tempo em que a presença de proteínas de peso molecular menor é mínima e essas não produzem reação no teste de diagnóstico.

No gel de SDS-PAGE foi identificada uma proteína de aproximadamente $36 \mathrm{kDa}$ presente em grande quantidade no extrato (Fig.1), confirmando a presença da proteína purificada. Vários antígenos têm sido utilizados para diagnóstico da infecção por B. mallei, sendo estes principalmente polipeptídeos (Wuthiekanun et al. 2002, Tyawisutsri et al. 2005). 0 perfil eletroforético do extrato obtido neste estudo está, em relação ao peso molecular, dentro do parâmetro encontrado nos extratos com alta imunogenicidade relacio-

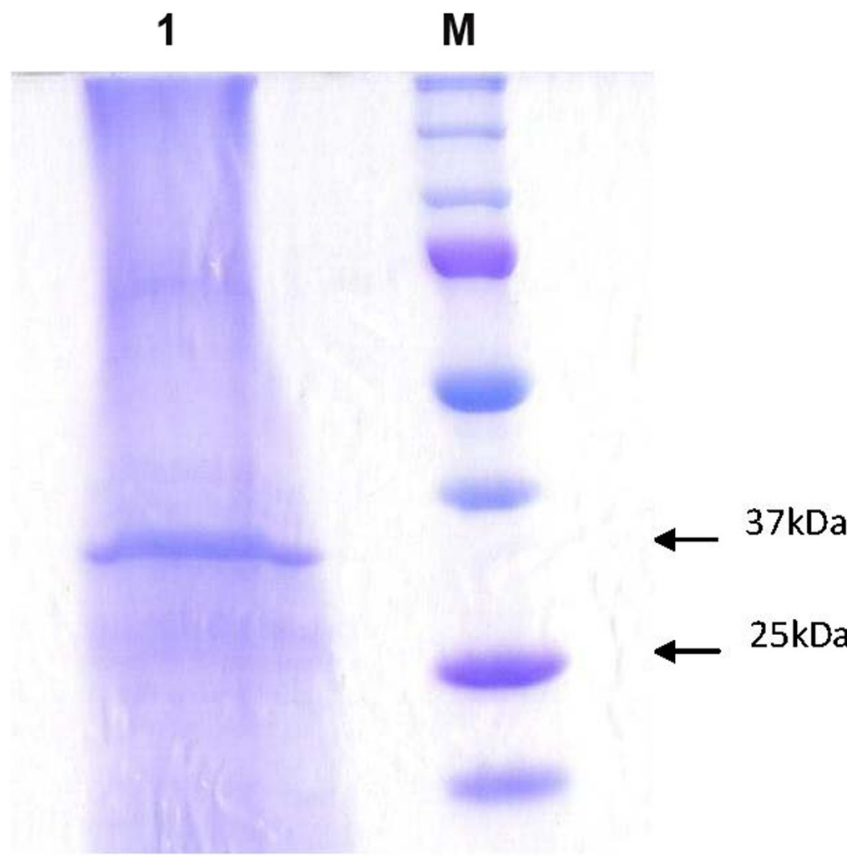

Fig.1. Perfil eletroforético em SDS PAGE de extrato proteico de Burkholderia mallei (maleína), onde: $\mathrm{M}=$ Marcador de massa molecular (Precision Plus Protein Dual Color Standards, Biorad); $1=10 \mu \mathrm{L}$ de extrato proteico de B. mallei. nados a B. mallei que ficam entre $26 \mathrm{kDa}$ e $48 \mathrm{kDa}$ (Verma et al. 1994, Anuntagool \& Sirisinha, 2002), implicando na possibilidade de êxito quando utilizado como antígeno em testes de diagnóstico.

A capacidade de produzir extratos de elevada imunogenicidade está relacionado à virulência da cepa de $B$. mallei utilizada. Um conjunto de 15 genes plasmidiais para produção de proteína capsular está relacionado à virulência de $B$. mallei e a inibição destes genes dão origem a cepas avirulentas (Schell et al. 2007). Estudos futuros são necessários para caracterizar essa proteína, bem como determinar seu potencial imunogênico através de immunobloting.

De acordo com Schell et al. (2007) um grupo de proteínas (Hcp-family), produzidas apenas durante a infecção natural e que estão relacionadas à virulência bacteriana podem ser detectadas por anti-soros de cavalos, humanos e camundongos infectados. $\mathrm{Na}$ análise isolada desta proteína em SDS-PAGE foram observados polipeptídeos de aproximadamente $22 \mathrm{kDa}$ que estão abaixo do produto encontrado neste estudo.

Os cobaios sensibilizados com B. mallei apresentaram anticorpos fixadores do complemento após 30 dias de inoculação confirmando a infecção. As duas proteínas (PPD) produziram reação intradérmica através da produção de edema no ponto de inoculação e em áreas adjacentes, aumentando de intensidade em 24 horas e atingindo pico máximo em 48 horas, período padrão para observação da reação na maleinização (Fig.2). Após 72 horas o edema proveniente do inóculo reduziu gradualmente. 0 padrão de reação a PPD-maleína foi homogêneo em todos os cobaios utilizados no teste de potência do produto; o edema foi persistente e não transitório, indicando a reação verdadeira positiva de acordo com a OIE (2008).

Verma et al. (1994) e OIE (2008) relataram que as PPDs-maleínas purificadas parcialmente podem ser amplamente utilizadas no diagnóstico do mormo devido a sua alta atividade maleinogênica. 0 teste intradérmico da maleína tem valor preditivo positivo de $92 \%$ nas infecções agudas e valor preditivo negativo de $96 \%$ nos casos crônicos, sendo a especificidade maior que a sensibilidade. A exclusão das reações falso-positivas é uma das vantagens da técnica (Al-

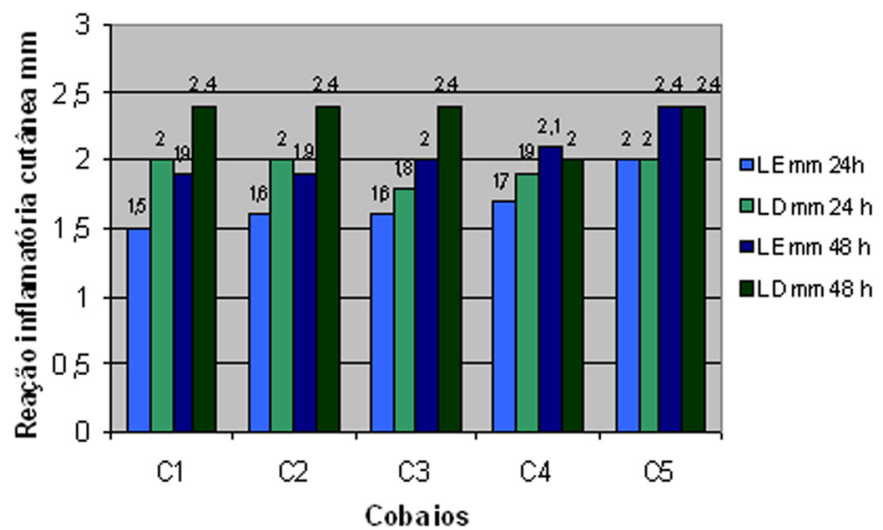

Fig.2. Avaliação das reações imunoalérgico-cutâneo resultantes das inoculações intradérmicas de PPD-maleína 1 e PPD-maleína 2 em cobaios. $\mathrm{LE}$ = lateral esquerda; $\mathrm{LD}$ = lateral direita; $\mathrm{mm}=$ 'milímetros. 
-Ani \& Roberson 2007), podendo a eficácia do teste variar proporcionalmente ao isolamento e purificação dos antígenos usados no kit de diagnóstico (Naureem et al. 2007). Casos muito avançados de mormo em cavalos podem produzir anergia ao teste e casos agudos em muares também podem proporcionar resultado não conclusivo necessitando o emprego de métodos adicionais de diagnóstico (Gregory \& Waag, 2009).

A capacidade na detecção da resposta imune celular da PPD-maleína produzida foi satisfatória quando avaliada biologicamente. Achados semelhantes também foram observados e descritos por Verma et al. (1994) com a PPD-maleína Indiana e Holandesa.

No G2 utilizado para avaliar a segurança das duas male- ínas não foram detectados anticorpos no teste de fixação do complemento antes da aplicação da maleína, assim como ausência de reação inflamatória em 24 e 48 horas após a inoculação da PPD-maleína 01 e PPD-maleína 02, caracterizando a segurança e ausência de reações falso-positivas. De acordo com a OIE (2008) para a maleína ser segura e não produzir resultados falso-positivos, o edema resultante do inóculo em cobaios ou equídeos não-infectados deve ser mínimo ou dificilmente detectável e transitório sem qualquer sinal de reação positiva.

As PPDs-maleínas foram avaliadas durante o processo experimental quanto à esterilidade, comprovando-se a ausência de contaminação do produto inoculado nos animais. Não houve efeito colateral à inoculação do imunógeno nos
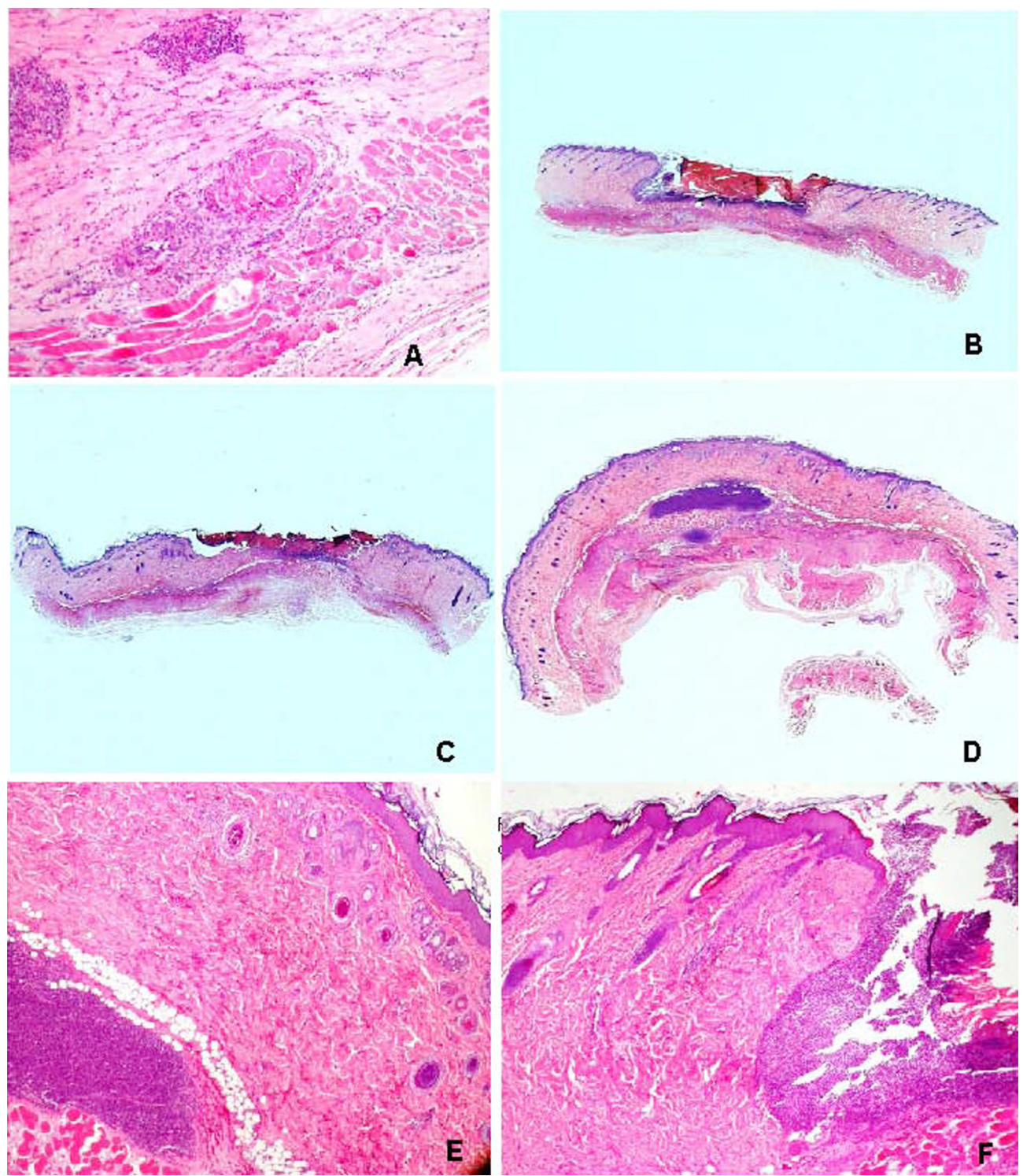

Fig.3. (A) Trombo e fibras musculares necróticas com discreto infiltrado mononuclear na pele. HE,obj.20x. (B) Pele com área localmente extensa de ulceração da epiderme e restos necróticos, limitada por infiltrado inflamatório predominantemente neutrofílico na derme profunda e subcutâneo. (D) Pele apresentando área localmente extensa de ulceração da epiderme com restos necróticos e infiltrado de neutófilos aglomerados na derme profunda e subcutâneo. (E) Pele com abscessos no subcutâneo. (F) Pele íntegra com abscesso no subcutâneo. HE, obj.20x. (G) Pele ulcerada com acentuada presença de infiltrado de neutrófilos na derme superficial e profunda. 
cobaios do G2, confirmando a inocuidade do produto (Ulrich \& Deshazer 2004, Mota et al. 2008).

Os achados histopatológicos foram semelhantes para ambas as PPDs-maleínas, não havendo diferenças macro e microscópicas significativas. Nos animais do G1, as lesões foram caracterizadas por dermatite ulcerativa e abscedativa, aguda, multifocal a localmente extensa, acentuada, associada a trombos, paniculite e necrose de fibras musculares esqueléticas adjacentes. Entre as fibras necróticas observou-se também infiltrado mononuclear (Fig.3). A reação inflamatória variou de moderada a acentuada de acordo com a gravidade do processo e sempre acompanhada por ulceração da epiderme. De acordo com Danneberg (1992), os eventos de HTT são importantes na defesa do hospedeiro, no entanto podem produzir necrose tecidual e a principal característica é o desenvolvimento do processo inflamatório mediado por linfócitos TCD4+ e a formação de infiltrado mononuclear que neste caso se comporta como a principal célula apresentadora de antígeno bacteriano para o linfócito.

Confirmou-se o desenvolvimento da HTT através da observação do infiltrado mononuclear na área do edema em todos os animais G1 quando comparado aos animais do G2 que não apresentaram tal reação tecidual. Esses achados histopatológicos constituem um dado importante para confirmar a resposta imunológica celular adquirida.

\section{CONCLUSÕES}

O processo utilizado para a produção, precipitação e purificação parcial da proteína, permitiu a obtenção de um produto com propriedades imunogênicas.

Os testes biológicos de avaliação da resposta imune celular demonstram que as duas PPD-maleínas testadas produziram reação positiva no teste intradérmico, identificando os animais sorologicamente positivos e excluindo os verdadeiramente negativos.

0 presente estudo atinge seu objetivo principal de produzir um reagente com potencial de uso no diagnóstico do mormo a partir de proteínas purificadas e derivadas de Burkholderia mallei isoladas no território nacional.

Agradecimentos.- Os autores agradecem ao Conselho Nacional de Desenvolvimento Científico e Tecnológico (CNPq) e a Fundação de Amparo à Ciência e Tecnologia do Estado de Pernambuco (FACEPE), pelo apoio financeiro para a realização dessa pesquisa.

\section{REFERÊNCIAS}

Al-Ani F.K. \& Roberson J. 2007. Glanders in horses: A review of the literature. Vet. Arhiv 77:203-218.

Amemiya K., Meyers J.L., Deshazer D., Riggns R.N., Halasohoris S., England M., Ribot W., Norris S.L. \& Waag D.M. 2007. Detection of the host immune response to Burkholderia mallei heat-shock proteins GroEL and DnaK in a glanders patient and infected mice. Diagn. Microbiol. Infect. Dis. 59:137-147.

Anuntagool N. \& Sirisinha S. 2002. Antigenical relatedness between Burkholderia pseudomallei and Burkholderia mallei. Microb. Immun. 46:143150.

Brasil 2004. IN no 12, de 29 de janeiro - Requisitos de qualidade para credenciamento e monitoramento de laboratórios para o diagnóstico sorológico do mormo. Ministério da Agricultura Pecuária e Abastecimento. <www.agricultura.gov.br> Acesso em 12 jan. 2010.
Brasil 20008. Ocorrência do Mormo no Estado de São Paulo. 1a Reunião Extraordinária da Câmara Setorial de Equideocultura - CNA. Ministério da Agricultura Pecuária e Abastecimento. <http://www.canaldoprodutor. com.br/sites/default/files/MORMO_MAPA.pdf> Acesso em 27 nov. 2013.

Burtnick M.N., Brett P.J. \& Woods D.E. 2002. Molecular and physical characterization of Burkholderia mallei 0 antigens. J. Bacteriol. 184:849-852.

Dannenberg A.M. 1992. Delayed-type hypersensitivity and cell mediated immunity in pathogenesis of tuberculosis. Immunol Today 13: 228 - 233.

Gregory B.C. \& Waag D.M. 2009. Glanders. Med. Aspect. Biol. Warfare 6:121-146.

Laemmli U.K. 1970. Cleavage of structure proteins during the assembly of the head of bacteriophage T4. Nature 22:680-685.

Mota R.A., Brito M.F., Castro F.J.C. \& Massa M. 2000. Mormo em equídeos nos Estados de Pernambuco e Alagoas. Pesq. Vet. Bras. 20:155-159.

Mota R.A., Silva L.B.G., Silva K.P.C., Silva Neto J.B., Cunha A.P. \& Nascimento Sobrinho E.S. 2005. Caracterización bioquimica y perfil de sensibilidad antimicrobiana in vitro de Burkholderia mallei aisladas de équido. Arqs Inst. Biológico, São Paulo, 72:7-11.

Mota R.A., Silva L.B.G., Cunha A.P., Sobrinho E.S.N., Pinheiro Jr J.W., Rabelo S.S.A. \& Oliveira A.A.F. 2008. Alterações clínicas em cobaias (Cavia porcellus) inoculados experimentalmente com isolados de campo de Burkholderia mallei de equídeos com mormo. Med. Vet. 2:1-9.

Naureen A., Saqib M., Muhammad G., Hussain M.H. \& Muhammad N. 2007. Comparative evaluation of Rose Bengal plate agglutination test, mallein test, and some conventional serological tests for diagnosis of equine glanders. J. Vet. Diagn. Invest. 19:362-367.

Neubauer H., Sprague L.D., Zacharia R., Tomaso H., Al Dahouk S., Wernery R., Wernery U. \& Scholz H.C. 2005. Serodiagnosis of Burkholderia mallei infections in horses. J. Vet. Med. B, Infect. Dis. Vet. Publ. Health 52:201-205.

OIE 2008. Manual of Diagnostic Tests and Vaccines for Terrestrial Animals. World Animal Health Organization. Oie.int/eng/en_index.htm 01:01-17.

Schell M.A., Ulrich R.L., Ribot W.J., Brueggemann E.E., Hines H.B., Chen D., Lipscomb L., Kim H.S., Mrázek J., Nierman W.C. \& Deshazer D. 2007. Type VI secretion is a major virulence determinant in Burkholderia mallei. Mol. Microbiol. 64:1466-1485.

Silva K.P.C., Takaki G.M.C., Mota R.A., Jará A.M.A.T. \& Teles J.A.A. 2008. Caracterização fenotípica, perfil da atividade antimicrobiana, identificação de fatores de virulência e toxicidade de Burkholderia mallei isoladas no estado de Pernambuco e alagoas. Anais XI Encontro Nac. Microbiol. Ambiental, X Simpósio Bras. Microbiol. Solo, Fortaleza, p.70. (Artigo completo)

Silva K.P.C., Mota R.A., Cunha A.P., Silva L.B.G., Leal N.C., Cavalcante Y.V.N., Teles J.A.A., Pereira, M.C.C. \& Freitas N.S. 2009. Caracterização fenotípica e molecular de amostras de Burkholderia mallei isoladas na Região Nordeste do Brasil. Pesq. Vet. Bras. 29:439-444.

Ulrich R.L. \& Deshazer D. 2004. Type III Secretion: a Virulence Factor Delivery System Essential for the Pathogenicity of Burkholderia mallei. Infect. Immun. 72:1150-1154.

Tyawisutsri R., Peacock S.J., Langa S., Limmathurotsakul D., Cheng A.C., Chierakul W., Chaowagul W., Day N.P. \& Wuthiekanun V. 2005. Antibodies from patientes with melioidosis recognize Burkholderia mallei but not Burkholderia thailandensis antigens in the indirect hemmaglutination assay. J. Clin. Microbiol. 43:4872-4874.

Verma R.D., Sharma J.K., Venkateswaran K.S. \& Batra H.V. 1990. Development of an avidin-biotin dot enzyme-linked immunosorbent assay and its comparison with other serological tests for diagnosis of glanders in equines. Vet. Microbiol. 25:77-85.

Verma R.D., Venkateswaran K.S., Sharma J.K. \& Agarwal G.S. 1994. Potency of partially purified malleo-proteins for mallein test in the diagnosis of glanders in equines. Vet. Microbiol. 41:391-397.

Wuthiekanun V., Anuntagool N., White N.J. \& Sirisinha S. 2002. Short report: A rapid method for the differentiation of Burkholderia pseudomallei and Burkholderia thailandensis. Am. J. Trop. Med. 66:759-761.

Yabuuchi E., Kosako Y., Oyaizu H., Yona I., Hotta H., HashimotoY., Ezaki T. \& Arakawa M. 1992. Proposal of Burkholderia genus and transfer of seven species of the Pseudomonas homology group II to the new genus. J. Microbiol. Immunol. 36:1251-1275. 